\title{
Review Article \\ Clinical Application of Mesenchymal Stem Cells and Novel Supportive Therapies for Oral Bone Regeneration
}

\author{
Miguel Padial-Molina, ${ }^{1,2,3}$ Francisco O'Valle, ${ }^{4,5,6}$ Alejandro Lanis, ${ }^{1,7,8}$ Francisco Mesa, \\ David M. Dohan Ehrenfest, ${ }^{1}$ Hom-Lay Wang, ${ }^{1}$ and Pablo Galindo-Moreno ${ }^{1,2,3}$ \\ ${ }^{1}$ Department of Periodontics and Oral Medicine, School of Dentistry, University of Michigan, Ann Arbor, MI 48109, USA \\ ${ }^{2}$ Department of Oral Surgery and Implant Dentistry, School of Dentistry, University of Granada, 18009 Granada, Spain \\ ${ }^{3}$ Research Group \#CTS-583 (Implantology and Periodontics), University of Granada, Junta de Andalucía, Spain \\ ${ }^{4}$ Department of Pathology, School of Medicine, University of Granada, 18009 Granada, Spain \\ ${ }^{5}$ Biopathology and Regenerative Medicine Institute (IBIMER), University of Granada, 18009 Granada, Spain \\ ${ }^{6}$ Research Group \#CTS-138 (Pathology), University of Granada, Junta de Andalucía, Spain \\ ${ }^{7}$ Private Practice, 8320000 Santiago, Chile \\ ${ }^{8}$ Implantology Program, University of San Sebastian, 8320000 Santiago, Chile \\ ${ }^{9}$ Department of Periodontics, School of Dentistry, University of Granada, 18009 Granada, Spain
}

Correspondence should be addressed to Pablo Galindo-Moreno; pgalindo@ugr.es

Received 16 January 2015; Revised 7 April 2015; Accepted 14 April 2015

Academic Editor: Giulio Gasparini

Copyright (C) 2015 Miguel Padial-Molina et al. This is an open access article distributed under the Creative Commons Attribution License, which permits unrestricted use, distribution, and reproduction in any medium, provided the original work is properly cited.

\begin{abstract}
Bone regeneration is often needed prior to dental implant treatment due to the lack of adequate quantity and quality of the bone after infectious diseases, trauma, tumor, or congenital conditions. In these situations, cell transplantation technologies may help to overcome the limitations of autografts, xenografts, allografts, and alloplastic materials. A database search was conducted to include human clinical trials (randomized or controlled) and case reports/series describing the clinical use of mesenchymal stem cells (MSCs) in the oral cavity for bone regeneration only specifically excluding periodontal regeneration. Additionally, novel advances in related technologies are also described. 190 records were identified. 51 articles were selected for full-text assessment, and only 28 met the inclusion criteria: 9 case series, 10 case reports, and 9 randomized controlled clinical trials. Collectively, they evaluate the use of MSCs in a total of 290 patients in 342 interventions. The current published literature is very diverse in methodology and measurement of outcomes. Moreover, the clinical significance is limited. Therefore, the use of these techniques should be further studied in more challenging clinical scenarios with well-designed and standardized RCTs, potentially in combination with new scaffolding techniques and bioactive molecules to improve the final outcomes.
\end{abstract}

\section{Introduction}

Hard and soft tissues in the oral cavity are constantly being challenged. As a consequence of infectious oral diseases, trauma, tumor or cyst resection, or congenital and developmental conditions (i.e., cleft palate defects), tooth loss results in the alteration of basic functional, aesthetical, and psychological needs. Mastication, speech, swallowing, and thermal and physical protection of important anatomical structures (i.e., brain, nerves, arteries, and veins) are diminished [1]. In these situations, tooth replacement by osseointegrated implants is an essential tool to restore the normal stomatognathic system. However, quantitative and qualitative proper bone architecture to allow successful implant treatment is, unfortunately, sometimes compromised. If the adequate bone is not restored previously to the implant treatment, it may lead to further complications $[2,3]$.

Bone deficiencies in the oral cavity differ enormously in extension and etiology, ranging from localized alveolar bone loss due to periodontal disease to extensive bone atrophy as a consequence of a variety of syndromes, including traumatic injuries and bone resorption associated with a number of 
benign or malignant tumors. Extensive bone deficiencies, in particular, are really challenging in the clinical setting [4].

Bone regeneration requires the migration of specific cells to the healing area to proliferate and provide the biological substrate for the new tissue to grow. Soluble factors, different cell types, extracellular matrix (ECM), and matricellular proteins mediate and coordinate this process. Initially, angiogenic signals and new vascular networks provide the nutritional base for tissue growth and homeostasis. Simultaneously, a three-dimensional template structure based on a proper extracellular matrix is synthesized and organized. This template will, later, support and facilitate the process of bone formation and maturation. Once those structures are established, the regenerated bone will go on under the normal homeostatic and modeling-remodeling processes [5, 6].

Although the exact mechanisms that regulate the bone regeneration process at the deepest biomolecular level are yet to be understood, several methods for predictable bone reconstruction have been proposed [7], ranging from autografts, to allografts, xenografts, and alloplasts. These techniques present different drawbacks including the limited availability of autografts and their associated morbidity in addition to the absence of cell populations carried by allografts, xenografts, and alloplasts, which determine poor osteoinductive properties. To overcome these limitations, the use of growth factors incorporated in carriers, the stimulation of the selective production of growth factors using gene therapy, and the delivery of expanded cellular constructs are being used in different areas of maxillofacial reconstruction [8] (Figure 1). Cell therapy approaches constitute one of the most promising instruments to enhance reconstruction of both hard and soft tissues.

Stem cells are unspecialized cells with the ability to proliferate and differentiate to multiple cell types when stimulated by both internal and external signals. Adult (somatic) stem cells that exhibit this plasticity are called pluripotent cells and can be found in bone marrow in the form of hematopoietic, endothelial, and mesenchymal (stromal) stem cells (MSCs). Other sources of MSCs in adult patients have been also identified such as adipose tissues (ASCs), lung, and teeth (perivascular niche of dental pulp and periodontal ligament) $[9,10]$ (Table 1). Mesenchymal and Tissue Stem Cell Committee of the International Society for Cellular Therapy proposes minimal criteria to define human MSC. Firstly, MSC must be plastic-adherent when maintained in standard culture conditions. Secondly, MSC must express CD105, CD73, and CD90 and lack expression of CD45, CD34, CD14 or CD11b, CD79a, or CD19 and HLA-DR surface molecules. Thirdly, MSC must differentiate to osteoblasts, adipocytes, and chondroblasts in vitro [11]. In this way, MSCs can produce bone, cartilage, fat, or fibrous connective tissue depending on their differentiation process [10] and, therefore, are of most interest in the area of dental implantology. Different technologies and application protocols are being studied in this area. However, it is still needed to identify the appropriate cell types, origin, and processing protocols as the most critical determinants to achieve successful outcomes [12]. Due to the limited availability of MSCs from bone marrow, ASCs are also being explored. Adipose tissue is a rich

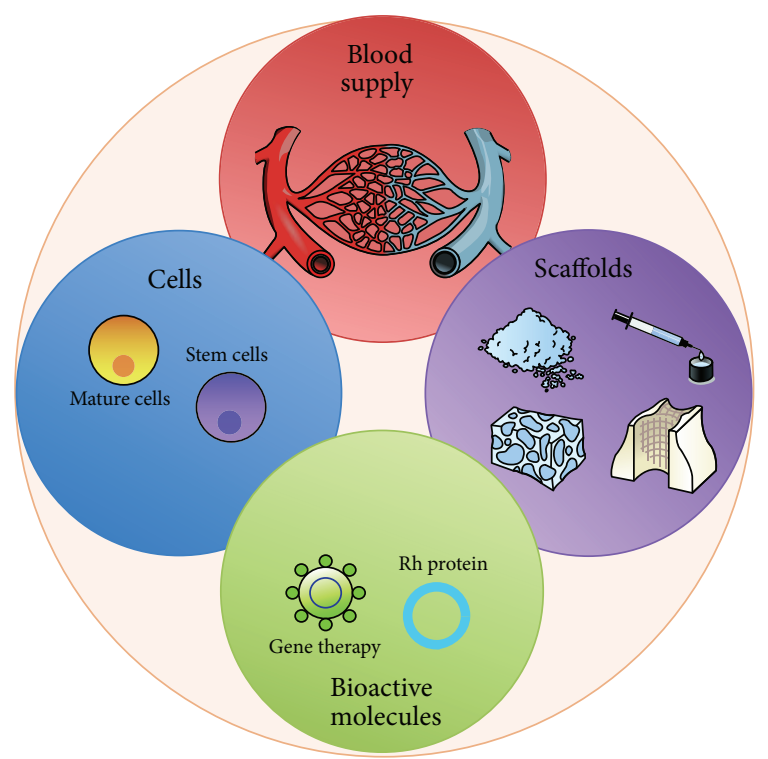

FIGURE 1: Schematic requirements for bone regeneration from a tissue engineering perspective.

TABLE 1: Principal types and uses of cells in oral tissue regeneration.

\begin{tabular}{ll}
\hline Cell type & Origin \\
\hline Bone marrow stromal cells & Autograft \\
Adipose stromal cells & Autograft \\
Periodontal ligament cells & Autograft, allograft, xenograft \\
Periodontal ligament stem cells & Allograft, autograft \\
\hline
\end{tabular}

source for multipotent stromal/stem cells (adipose-derived mesenchymal stromal/stem cells or ASCs) and has several advantages compared to other sources of mesenchymal stro$\mathrm{mal} / \mathrm{stem}$ cells (ubiquitous available, easy accessible source by liposuction, and more abundant $0.5-2 \times 10^{6} \mathrm{AScs} / \mathrm{g}$ adipose tissue) $[13,14]$.

Therefore, the main purpose of this review is to identify the existing literature on clinical studies utilizing MSCs or ASCs to treat oral bone defects and to critically analyze their validity, methodology, and outcomes. Additionally, emerging strategies for the recruitment and transplantation of MSCs into bone defects will also be discussed.

\section{MSC-Based Bone Regeneration}

2.1. Materials and Methods. A search of electronic databases including Ovid (MEDLINE), PubMed, and Cochrane Central for studies was performed in September 2014 by two examiners limited to articles published in English during the last 10 years performed on human subjects. The search build used was as follows: ("Mesenchymal Stem Cell Transplantation" [Mesh] OR "Adult Stem Cells" [Mesh] OR "Stem Cells" [Mesh] OR "Stem Cells Transplantation" [Mesh] OR “Tissue Therapy" [Mesh] OR "Bone Marrow Transplantation” [Mesh] OR "Bone Marrow" [All Fields] OR "stem cell therapy" [All Fields] OR “stem cell” [All Fields]) AND ("Sinus Floor 
Augmentation" [Mesh] OR "Bone Regeneration" [Mesh] OR "Alveolar Ridge Augmentation" [Mesh] OR "craniofacial bone regeneration" [All Fields] OR "craniofacial" [All Fields] OR "alveolar bone" [All Fields] OR "implant site development" [All Fields]) AND ((Controlled Clinical Trial [ptyp] OR Clinical Trial [ptyp] OR Randomized Controlled Trial [ptyp] OR Case Reports [ptyp] OR Comparative Study [ptyp] OR Validation Studies [ptyp] OR Evaluation Studies [ptyp]) AND “2004/09/12” [PDat]: "2014/09/12” [PDat] AND "humans" [MeSH Terms] AND English [lang]).

In addition, a manual search was conducted in related scientific journals and relevant papers that could contribute to the process of information collecting.

The following inclusion criteria to select the articles obtained after the search were as follows: human clinical trial (randomized or controlled) and case reports/series on the clinical application of MSCs in oral bone regeneration. On the other hand, articles were excluded if the technique applied was related to periodontal regeneration or was not associated with bone tissue reconstruction. Articles were first screened by analyzing the abstract. From those which were selected in this phase, full-text was obtained and analyzed for a second screening. Potential articles were independently reviewed in full-text by two examiners. The final decision on the included articles was made with mutual agreement of the two examiners.

Additionally, a critical review of relevant supportive technologies for bone regeneration in combination with MSCs has been conducted.

2.2. Results. A total of 190 records were identified by the database and hand search and were assessed for eligibility. After reading the abstracts, 51 articles were selected for fulltext assessment. Of those, only 28 were included in this review based on the inclusion criteria previously determined. From the 28 articles selected (Figure 2), 9 corresponded to randomized controlled clinical trials [15-23] (Table 2), 9 to case series [24-26, 32, 36-40], and 10 to case reports [27$31,33-35,41,42]$ (Table 3). Collectively, they evaluate the use of MSCs in a total of 290 patients/342 interventions. However, due to the high variability among different variables, a metaanalysis was not considered appropriate.

Bone deficiencies in the oral cavity differ enormously in extension and etiology, ranging from localized alveolar bone loss due to periodontal disease to extensive bone atrophy as a consequence of a variety of syndromes, including traumatic injuries and bone resorption associated with a number of benign or malignant tumors. In these clinical scenarios, functional and esthetical rehabilitation by dental implants is an essential tool. However, a proper quantity and quality of bone is a prerequisite not always present [1]. Therefore, different regenerative techniques have been proposed in these scenarios aiming at achieving predictable outcomes. Extensive bone deficiencies, in particular, are really challenging in the clinical setting. Fortunately, cell transplantation strategies can provide a viable treatment option to overcome the limitations of autograft harvesting and the reduced colonization of nonautograft materials and

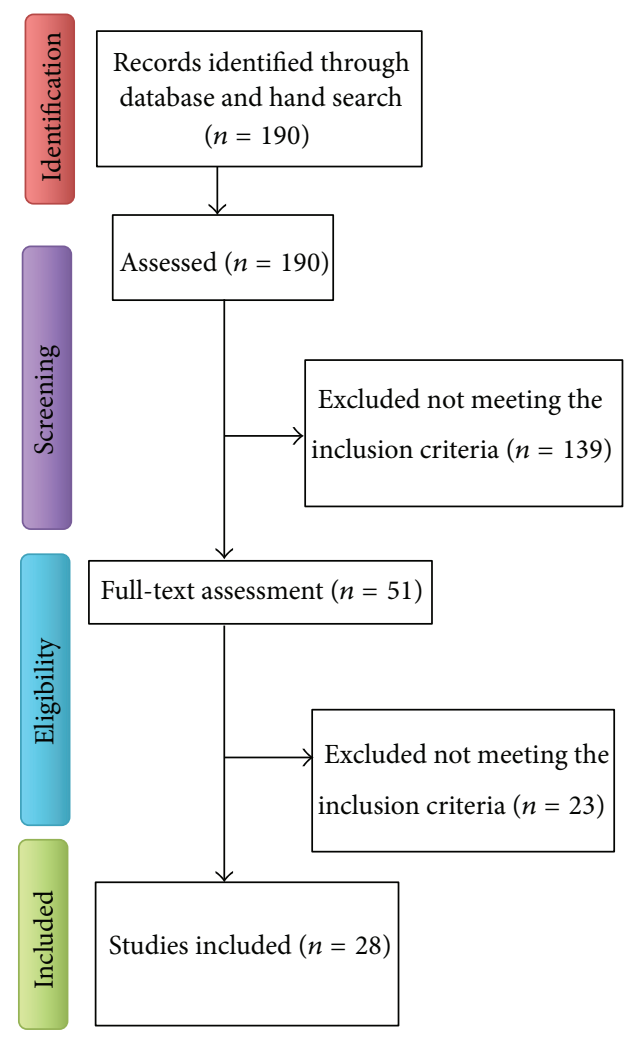

Figure 2: Flow chart of the paper selection process.

constitute one of the most promising instruments to enhance reconstruction of both hard and soft tissues [43,44].

Bone regeneration requires not only osteolineage populations to migrate, proliferate, and differentiate into the treated area but also, of extreme importance, angiogenesis to provide the adequate nutrients and environment in which the bone tissue can grow and develop [12, 45]. Because of this, stem cells have gained interest due to their capacities to differentiate to a variety of cell lineages, including hematopoietic, mesenchymal, and endothelial cells [10]. Stem cells can be found in different tissues, such as bone marrow, adipose tissue, and, in the oral cavity, periodontal tissue, dental pulp, and dental follicle [8] (Table 1). However, due to the limited autogenous availability in some of those locations, only bone marrow and adipose-derived mesenchymal stromal/stem cells have been clinically applied to bone regeneration in the oral cavity. Although different technologies and application protocols are being studied in this area, the optimal cell type, origin, and processing protocol are yet to be identified [12].

The analysis of the published literature on the clinical use of MSCs for oral bone regeneration previous to dental implant placement highlights the lack of proper RCTs with comparable methodologies to extract proper overall conclusions. However, out of the 28 identified clinical studies, 25 report the use of iliac bone marrow aspirates (BMA) which reflects that this location is widely accepted as the current standard for aspirate harvesting [16-30, 33-42]. In fact, BMA from the iliac crest has been confirmed as the harvesting 


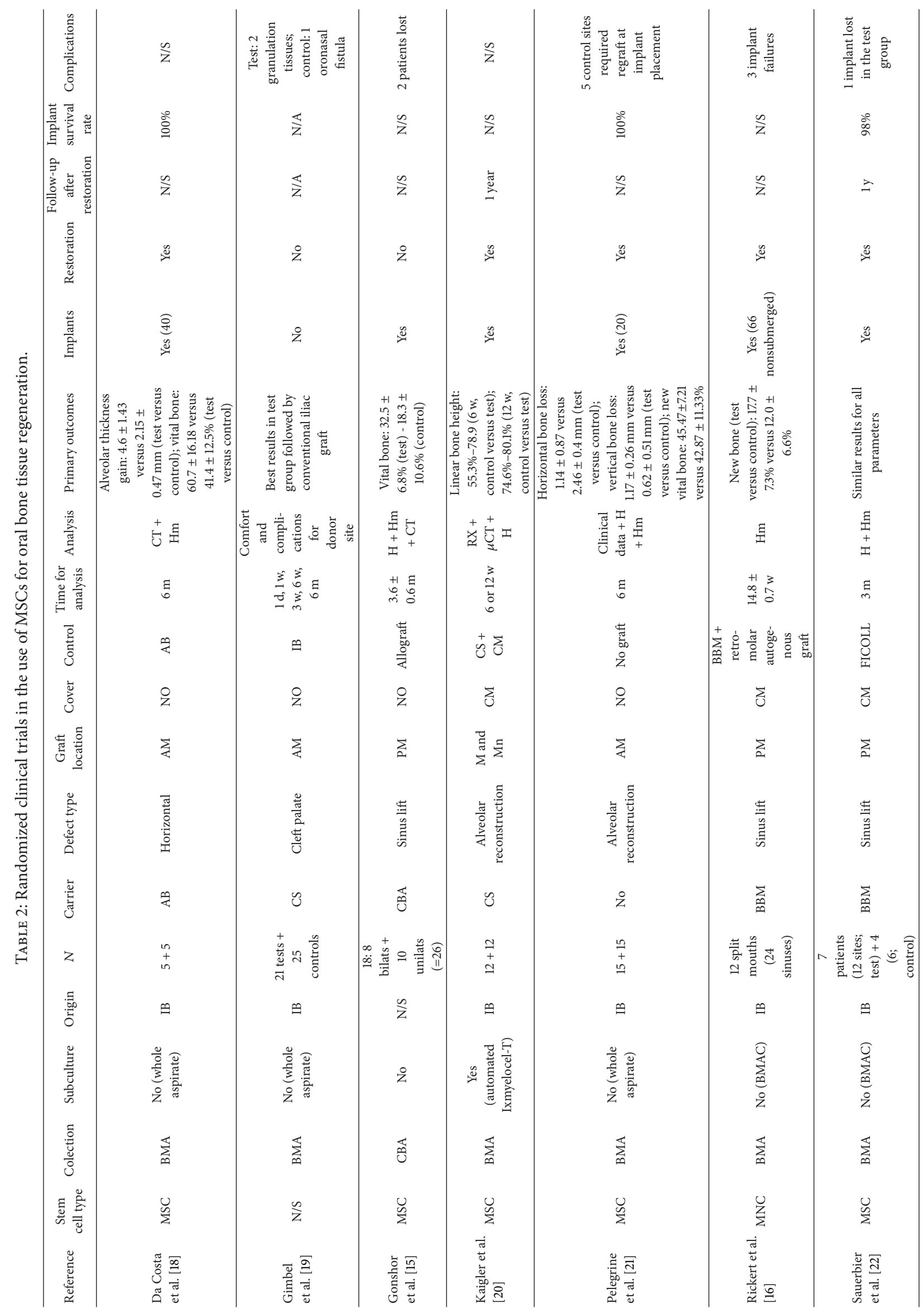




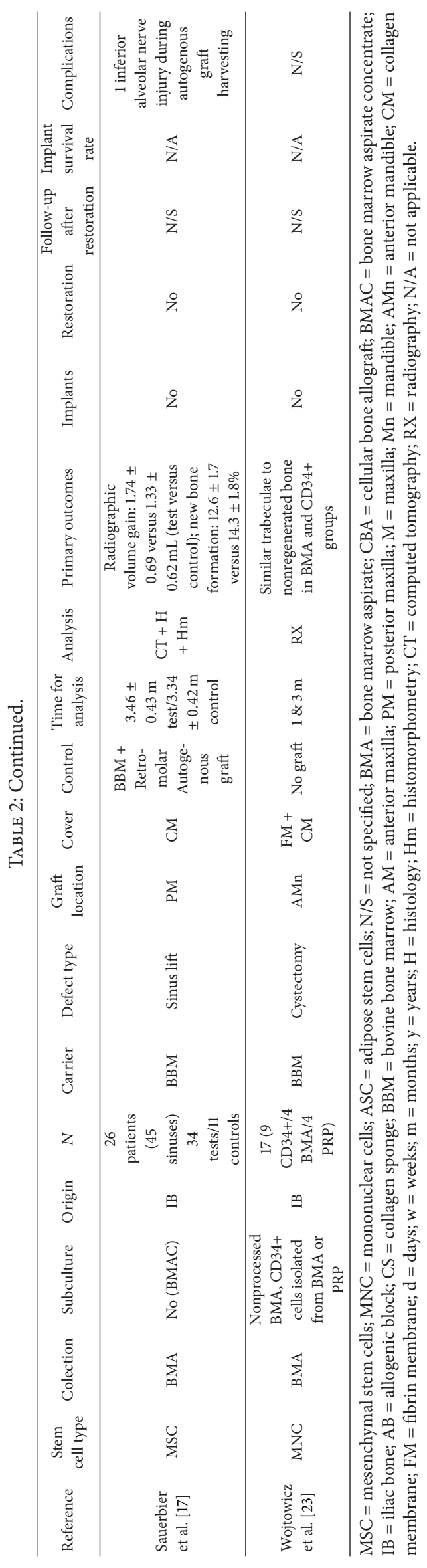




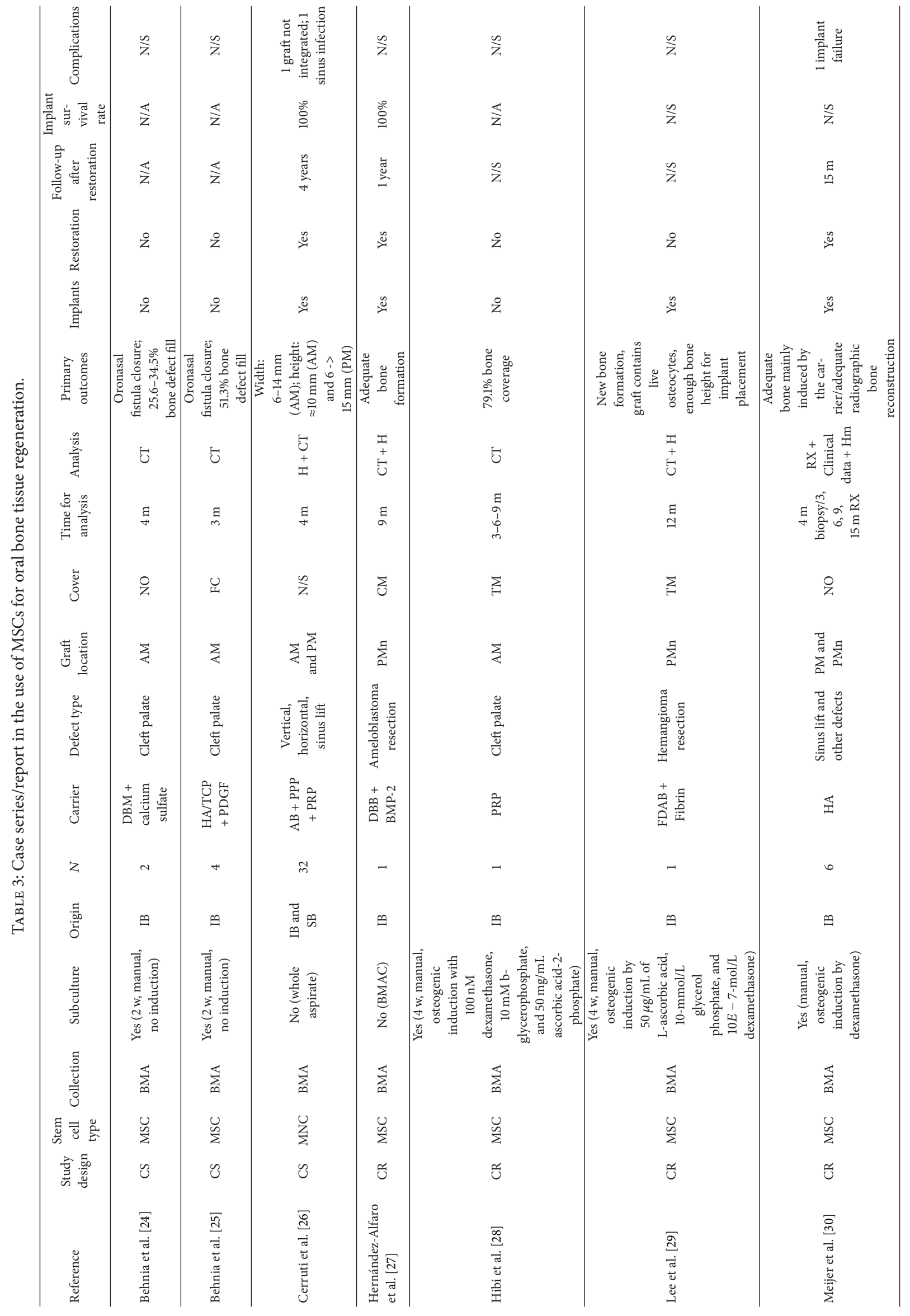




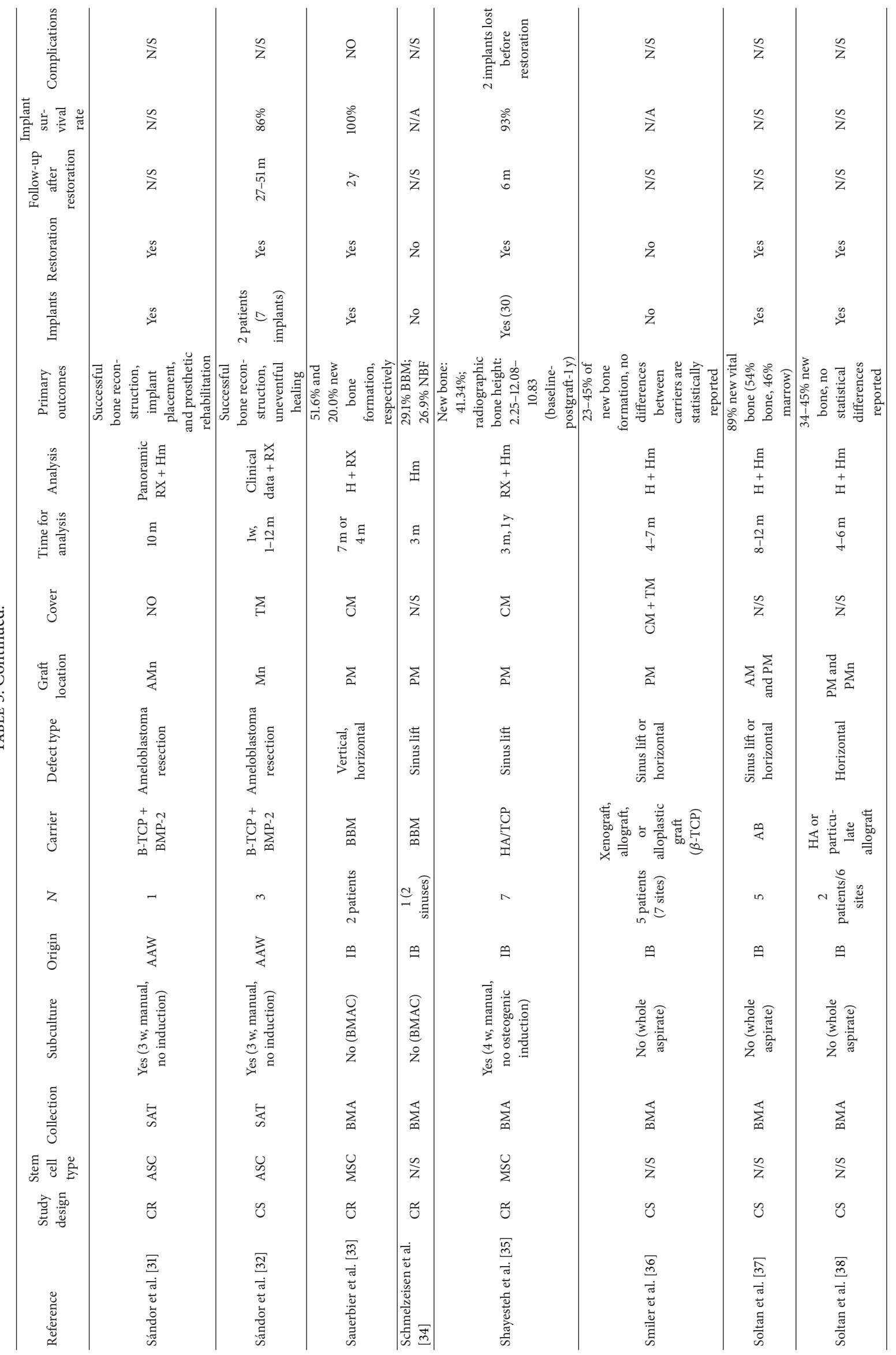




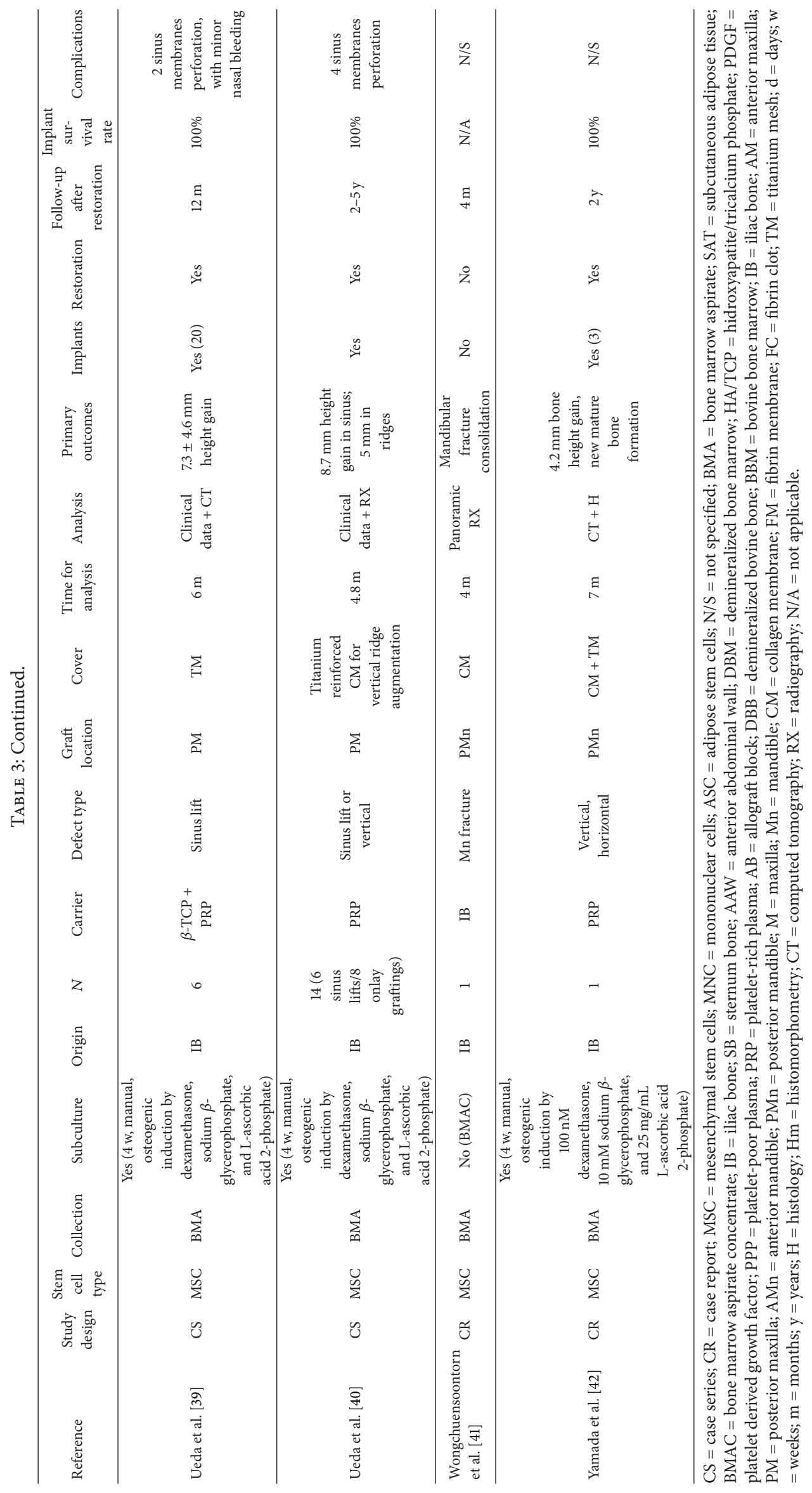


technique with less morbidity and better patient comfort than the traditional bone harvesting from the same location [19].

However, there is no standardization in terms of the processing and handling of such aspirates. While some studies use an expansion and isolation protocol previous to the surgical implantation (with a variety of subculture times, culture supplementations, automated or manual processes, cell population selection, etc.), others do the aspirate intrasurgically (chairside) and use the whole aspirate or a commercially available concentration kit (to select endothelial progenitors, hematopoietic and mesenchymal stem cells, platelets, lymphocytes, and granulocytes) (BMAC Harvest Technologies Corporation, Plymouth, MA, USA). One RCT compared the use of nonprocessed BMA versus PRP or CD34+ cells (angiogenic cells isolated from a BMA). Radiographic results from this study confirmed the utility of BMA and CD34+ over PRP alone [23]. However, to our knowledge, no clinical comparison has been done between processed BMA and nonprocessed BMA, which will be of high interest. In this sense, results from 2 RCTs $[20,21]$ show a similar achievement in postextraction socket reconstruction in terms of horizontal and vertical augmentation, even though the cell concentration procedure was performed by an automatic cell culture system (that specifically increases the proportion of bone repair cells, that is, hematopoietic and mesenchymal stem cells) (Ixmyelocel-T, Aastrom Biosciences Ann Arbor, MI, USA) [20] or a chairside technique including the whole aspirate with no concentration step [21].

Another important difference amongst studies is the carrier used to deliver the cells. It ranges from alloplastic graft ( $\beta$-TCP or HA) to xenograft (mainly bovine bone), allograft or autograft (either PRP concentrate or autogenous bone). Other studies use a combination of those materials, with or without the addition of additional factors such as PDGF or BMP-2. No standardization is found on the use of a covered membrane over the grafted area either.

Additionally, different defects are being treated in these studies. Those defects range from extensive non-selfcontained (cleft palate and tumoral postresection defects) to extensive self-contained (sinus lift), nonextensive selfcontained (postextraction sockets), and nonextensive nonself-contained defects (vertical and horizontal alveolar ridge augmentation). Bone regeneration in these situations differs enormously from one to another.

Globally, the results in most of the available literature show the goodness of the technique by vague subjective indications of qualitative appreciations and some studies fail to report specific objective quantitative data. When they do, the reported data is not comparable either as it ranges from vertical, to horizontal, or volumetric measures. Additionally, these measures are presented in absolute magnitudes or $\%$ of gain or reduction depending on the study. On the other hand, the number of differences among the identified RCTs makes it difficult to make a fair global comparison. Only 2 of those RCTs are fairly comparable as they use similar methodologies for concentration process (chairside), cell origin (iliac crest), defect type (sinus lift), and control group (bovine bone + autogenous graft) $[16,17]$. From both studies that globally treated 69 sinuses (46 tests and 23 controls) in 38 patients,

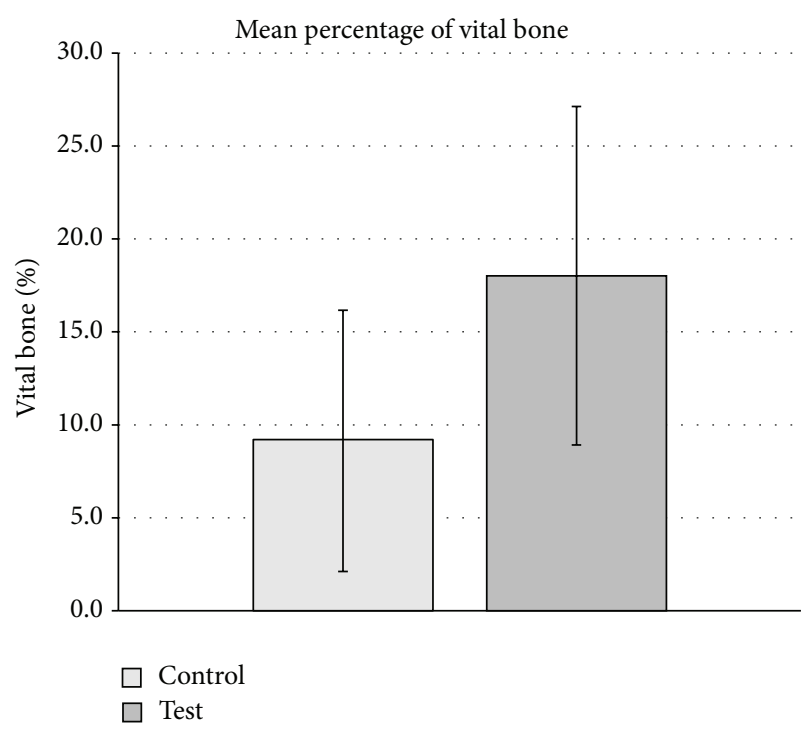

FIGURE 3: Weighted mean percentage of vital bone from RCTs on sinus lift [15-17]. No overall statistical significance difference was found ( $p=0.085$, Student's $t$-test).

it can be concluded that the combination of bovine bone plus BMA concentrated chairside provides a higher radiographic volume gain of $1.74 \pm 0.69$ versus $1.33 \pm 0.62 \mathrm{~mL}$ (test versus control, $p<0.02$ ) [17] and better histological outcomes in terms of new bone formation $17.7 \pm 7.3$ versus $12.0 \pm 6.6 \%$ (test versus control, $p<0.026$ ) [16]. Sauerbier et al. [17] reported no histological differences $(12.6 \pm 1.7$ versus $14.3 \pm 1.8 \%$; test versus control, $p=0.333)$. Other studies on sinus lift also show histological advantage of using stem cells carried in an allograft cellular bone matrix in this location (new vital bone: $32.5 \pm 6.8 \%$ versus $18.3 \pm 10.6 \%$, test versus control) [15]. The weighted mean percentage of vital bone obtained by these studies is not statically different from control $(9.14 \pm 7.02)$ to test group (18.02 \pm 9.1$)$ ( $p=0.085$, Student's $t$-test) (Figure 3). The differences are even more diffuse if other studies treating other defect locations are included in this comparison. This highlights the necessity for better-designed studies to reduce bias and variety of data and ultimately enables consensus in this field.

In summary, the main overall report findings were that the clinical application of stem cells for oral bone regeneration promotes better outcomes in terms of clinical, radiographic, and histological parameters. However, the clinical significance in the applications analyzed in those RCTs (mainly self-contained defects, that is, postextraction sockets and sinus floor elevation) is very limited. Therefore, it could be argued that (1) the use of stem cells is not necessary in small defects that can be successfully treated by other means and (2) the lack of conclusive advantages does not surpass the scientific doubts, morbidity, and potential complications that stem cell therapy may possess. Therefore, the generalizability for the use of stem cell therapy in the daily clinical setting is still to be confirmed and probably not recommended for many clinical cases. Its advantages are yet to be studied in more challenging scenarios, such as extensive non-self-contained 
defects (vertical alveolar bone augmentation, extensive bone deficiencies in postresection tumor defects, and cleft palate conditions) where they may show their greatest potential over current treatment options.

\section{Novel Supportive Strategies for the Use of MSCs in Bone Regeneration}

The clinical use of MSCs for oral bone regeneration is usually accompanied by supporting scaffolds and bioactive molecules to further increase the capabilities of cell-based therapies.

3.1. Scaffolds for Bone Regeneration. The main purpose of a scaffold is to provide a mechanical support for cell migration, proliferation, and activity by mimicking the ECM. They will stimulate the production and maturation of a new ECM that will eventually mineralize. A scaffold will ideally provide a template for the subsequent bone formation, which starts in the periphery and continues towards the inner part. In this process, porosity is of extreme importance since it will facilitate cell ingrowth and vascularization and the biodegradation process [46]. Additionally, surface chemistry, surface charge, and topography are also important in the interactions between cells and material for bone tissue growth $[5,47]$.

Conventional scaffolds naturally derived (autografts, allografts, and xenografts) or synthetic materials (alloplasts) are commonly used in bone regeneration and implant therapy [5]. However, clinical needs of full control of the regeneration process, focus, and orientation and in large defects cannot be successfully achieved by this classic or conventional approach. Fortunately, additive manufacturing processes allow full control of porosity features, 3D structure, and surface properties of the synthesized material and it is, therefore, being the focus of extensive research [48]. They can be combined with cell-, growth factor- or genebased approaches to serve as supportive carriers and induce stimuli for tissue formation [49]. 3D printed scaffolds can also mimic stem cell niches to regulate daughter cell proliferation, differentiation, and dispersion into the surrounding tissue or by attracting useful cells to a desired anatomic site [49, 50].

Additive manufacturing is defined as the process of joining materials to make objects from $3 \mathrm{D}$ model data, usually layer upon layer, as opposed to subtractive manufacturing methodologies [51]. Usually, 3D printing is used as a synonym since it is the most widely used. However, additive manufacturing also includes other scaffold fabrication techniques such as solid freeform fabrication (SFF) and rapid prototyping (RP) that use deformation and solidification, polymerization, laser-assisted sintering, or direct writingbased processes to create the final scaffold [52]. Additive manufacturing relies upon computer-based scaffold design and fabrication [53]. This image-based design technology can be used to define virtual three-dimensional models of anatomic geometry of the defect and to create a template for the scaffold on a global anatomic level [54]. By additive manufacturing, the heterogeneous structures to be regenerated can be mimicked by variations in macro-, micro-, and nanostructures and scaffold surface topography, which will influence the modulus of elasticity, permeability, and cell orientation [55-57].

For bone regeneration, a large variety of ceramic, polymeric, and composite materials can be processed using $3 \mathrm{D}$ printing to control interconnected porosity [52]. Among these, calcium phosphates are the main materials used in bone engineering. Of them, hydroxyapatite (HA) is the most used and studied ceramic material in the dental field [8]. HA possesses an excellent bioactivity, osteoconductivity and is similar to bone in composition. It can stimulate BMP2 expression in a pathway dependent on the p38 MAP kinase [58], increase of capillaries and vessel formation, and homogeneous osteoconduction from central channels with no cytotoxicity and adequate cell adhesion [59]. Hydroxyapatite customized scaffolds can be combined with MSCs to achieve better results than those obtained with controls [60]. Similarly, $\beta$-tricalcium phosphate, a synthetic inorganic calcium-phosphate-based material, has demonstrated an increase of human osteoblasts ingrowth, proliferation, and new bone formation [61] with adequate biocompatibility also confirmed by tartrate resistant acid phosphatase (TRAP) staining and lacunae formation [62].

Synthetic polymers in bone tissue engineering are very flexible [63]. Property modification, control of macrostructure, degradation time and release mechanism, and exposure duration of bioactive molecules can be better controlled with these materials [64-66]. It is possible to maintain the therapeutic levels of encoded proteins and to limit unwanted immune response and potential side effects. The most studied synthetic materials for additive manufacturing are the group of poly(lactic-co-glycolic acid)based (PLGA) biomaterials. This material has been successfully used for the regeneration of complex bone-ligament interfaces with rapid prototyping techniques [54, 55, 67]. Other polymers under study are the group of poly(ethylene glycols) and poly( $\varepsilon$-caprolactone) methyl ethers. They can be combined with cell transplantation and hydroxyapatite to increase the mimetic properties and, therefore, improve bone regeneration results, specifically in terms of mechanical strength [68].

Based on these properties, the use of $3 \mathrm{D}$ printing in fabricating scaffolds with live osteoprogenitor cells [69] and the controlled delivery of specific growth factors such as BMP-2 [59, 70], collagen, and chondroitin sulfate [71] or other drugs like tetracycline [72] are being explored. The potential application is to reduce the dose of those molecules, control the release pattern, and reduce side effects. Bioprinting, however, is still at a very early stage and much research is yet to be done.

3.2. Bioactive Molecules and Gene-Therapy Techniques. The delivery of growth factors and other bioactive molecules was the first approach into using a biological agent modifier for regeneration purposes [73]. A number of factors, such as platelet derived growth factor (PDGF), fibroblast growth factor (FGF), insulin growth factor (IGF), bone morphogenic 


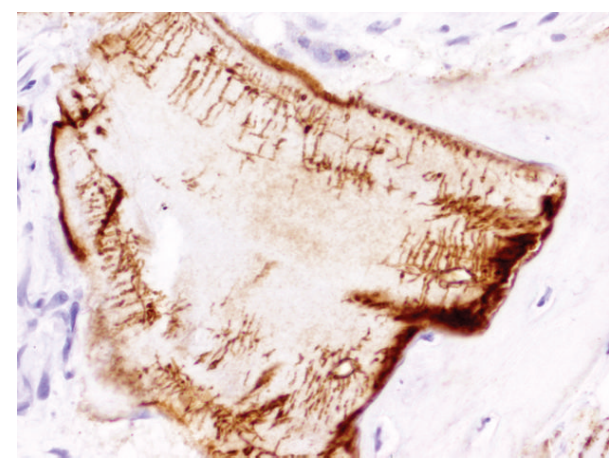

FIGURE 4: Osteopontin immunohistochemical detection on anorganic bovine bone particle (Bio-Oss). Note bone formation where intense interstitial expression of OPN is observed in a case of maxillary sinus floor elevation (micropolymer peroxidase-based method, original magnification $\times 20$ ).

proteins (BMPs, specially BMP-2 and BMP-7), periostin, vascular endothelial growth factor (VEGF), and transforming growth factor beta (TGF- $\beta$ ), are present in the healthy bone matrix and are expressed during bone healing [74]. They regulate vascularization and induce proliferation and differentiation of osteoprogenitors cells $[52,61,70]$ and surrounding tissues in the periodontal and gingival structures [75-78]. Therefore, they can be useful for improving the healing processes and to stimulate bone regeneration and have extensively studied and reviewed elsewhere $[8,49]$.

In addition to the mentioned growth and/or transcription factors and regulators of osteogenesis, our group has recently initiated efforts in investigating the potential of two molecules that can be of interest in this topic as well. Osteopontin (OPN) is a highly phosphorylated sialoprotein abundant in the mineralized extracellular matrices of bones and teeth [79]. OPN, mainly through its RGD region, stimulates cell activity to influence, amongst others, bone formation, remodeling, and maintenance as well as angiogenesis [80]. In bone, it is primarily synthesized by cells of osteoblastic lineage and in wound healing sites [81] where it interacts with the cellsurface receptor CD44 [82]. This interaction has been shown to increase MSCs recruitment to the bone healing area [83]. Previous findings related OPN expression to the presence of CD44-positive cells in anorganic bovine bone (ABB) particles in samples from sinus floor augmentation. OPN was found on the interstitial boundary of new bone with $\mathrm{ABB}$, inside lacunae spaces, bone canaliculi and in osteocytes in trabecular bone without expression in the trabecular bone or the interstitium $[84,85]$. Therefore, combining scaffold modification with the delivery of bioactive molecules, it could be possible to include OPN in ABB particles to increase bone regeneration in vivo (Figure 4).

Another important attractor of MSCs to the bone healing area is Musashi-1. Musashi-1 is an osteogenic marker expressed in osteoblasts (cytoplasm and nuclei) and osteocytes (nuclei) (Figure 5). It binds to RNA as a translational regulator in MSCs with osteogenic capacities. It could therefore be delivered to increase recruitment and differentiation

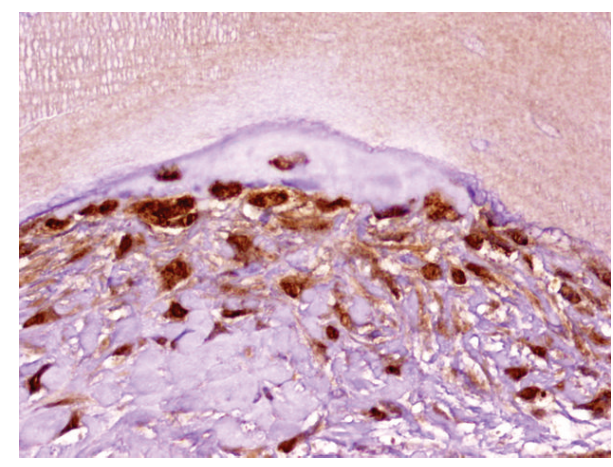

FIGURE 5: Immunohistochemical expression of Musashi-1 in fusocellular cells, osteoblasts, and osteocytes in a case of maxillary sinus floor elevation with anorganic bovine bone (micropolymer peroxidase-based method, original magnification $\times 20$ ).

of osteogenic MSCs [86]. These activities are still at their very infancy and more research is needed.

However, an important drawback of these described methods is the difficulty in activating the right process at the right location in the right cells at the right time for a sufficient amount of time, while minimizing adverse reactions [87]. Important advances have been made to overcome these limitations. Some of the most promising strategies are those designed to activate the protein release from the scaffold [88] or the activation of the bioactive molecule [89] "on demand" by an external source or trigger. Different methodologies are under study, including the activation by changes in $\mathrm{pH}$, proteases activity, and energy-based stimuli such as magnetism, electricity, light, and temperature [88]. Focused ultrasound is an emerging clinical technology primarily used for the thermal and/or mechanical ablation of cancerous or precancerous tissues deep within the body that can be focused on small volumes and generate spatially restricted regions of hyperthermia by coupling a magnetic resonance imaging (MRI) instrument to an integrated high intensity focused ultrasound (HIFU) transducer. HIFU has also been successfully used to achieve spatial and temporal control of the production of VEGF and BMP-2 in vitro and in vivo $[89,90]$. With such technology, scaffolds, cells, bioactive molecules, and gene therapies could be suitable for a $4 \mathrm{D}$ control. The implications of this approach range from the identification of spatiotemporal patterns of gene expression during development to, more importantly within the aim of this review, the application of those patterns for bone regeneration in vivo as a future clinical tool.

\subsection{Perspectives on Platelets and Fibrin Gels for Combined} Therapies. In last decades, many different approaches have been attempted for the use of autologous platelet concentrates that serve as both carrier and metabolic stimulators through their high concentration of growth factors [91]. Despite the specific differences between them in terms of concentration procedure, coagulant treatment, separation of blood phases, and so forth [92], they have been tested in many different 
clinical fields, such as oral and maxillofacial surgery, earnose-throat surgery, plastic surgery, orthopaedic surgery, sports medicine, gynecologic and cardiovascular surgery, and ophthalmology [91, 93]. In the literature, their clinical and experimental results are often controversial and difficult to sort and interpret $[94,95]$, mostly because of the lack of proper terminology between many different families of products, often wrongly regrouped under the inaccurate generic term PRP (platelet-rich plasma) [92]. Recent terminology and classification regrouped these techniques into 4 families depending on their fibrin architecture and cell content [92, 96, 97]: pure platelet-rich plasma (P-PRP), leukocyte- and platelet-rich plasma (L-PRP), pure platelet-rich fibrin (PPRF), and leukocyte- and platelet-rich fibrin (L-PRF).

The 2 families of PRPs are first of all platelet suspensions, which can jellify after activation like a fibrin glue [96, 98]; as it was discussed previously, the PRP fibrin gels were tested as scaffolds for MSCs, as fibrin gels are quite common scaffolds in tissue engineering [91]. On the other hand, the 2 families of PRF only exist in a strongly polymerized fibrin gel form [99]. P-PRP and P-PRF do not contain leukocytes or any other cell bodies outside of platelets, while L-PRP and L-PRF contain leukocytes and various populations of circulating cells [99].

This classification is interesting to correlate with Figure 1, as it highlights the fact that the products from the LPRF family present all the schematic requirements for bone regeneration from a tissue engineering perspective: cells (leukocytes and many other cell populations) [99], scaffold (fibrin blood clot, often used in bone tissue engineering experiments) [100], and bioactive molecules (growth factors and all the molecules available in platelets, plasma, and leukocytes for starting) [101]. L-PRF has also this particularity to integrate very naturally all these elements, leading to the slow release of growth factors from the L-PRF fibrin matrix and the production of growth factors from the cells living in the gel $[98,101,102]$. For these reasons, L-PRF was often described as an optimized natural blood clot [99], and, as it is often said in orthopedics, there is no good bone healing without adequate bleeding.

Specifically, within the context of this review, it is important to highlight the fact that L-PRF was tested with oral bone mesenchymal stem cells in vitro [103] and revealed itself as a dose-dependent stimulator of proliferation and differentiation of these cells. This result was described also in other studies with osteoblasts [100]. It was considered as the consequence of the coculture between the bone cells and the leukocytes of the L-PRF $[100,103]$, in the presence of the fibrin matrix and growth factors of the L-PRF clots [98], resulting in complex but natural interactions promoting bone regeneration. L-PRF is therefore in itself an interesting model fulfilling the requirements for bone regeneration presented in Figure 1, and it probably explains that it has been demonstrated to be successful in the treatment of bone defects [94, 95, 104-106], for example, as sole grating material in maxillary sinus floor elevation [107-109]. As an interesting perspective of combined therapy, it seems that one promising novel supportive strategy for the use of MSCs in bone regeneration may be as simple as an optimized L-PRF natural blood clot.

\section{Conclusion}

Bone regeneration based on tissue engineering approaches has a solid background for clinical application in human bone defects. The cell-based, scaffold, bioactive molecule delivery and gene-therapy methods interface and complement each other. However, some of these therapies are still at the preclinical level.

As presented in this paper, many different approaches and biologic agents are being studied. The major challenge for all of them is the timely and sequential organization of events that need to occur in the healing area. The aim is to promote the adequate processes at the precise moment without compromising the normal cell function and overall process. External "on demand" activation technologies are being developed. Additionally, the need for custom medical devices that can be adapted for the patient and the bone defect specific clinical needs will increase the use of $3 \mathrm{D}$ printing in the coming years. The association of these techniques with cell-based, bioactive molecules and gene-therapy approaches is a promising and exciting area of research.

However, the current published literature on the clinical application of stem cells for craniofacial bone regeneration is abundant but highly diverse, which reflects (1) the fact that these technologies are relatively new and, therefore, it is difficult to standardize findings and clinical applications; and (2) the number of different potential applications to successfully use cell therapy in the clinical practice is high but still needs to be scientifically proven.

\section{Conflict of Interests}

The authors declare that there is no conflict of interests regarding the publication of this paper.

\section{Acknowledgments}

The authors of this paper were partially supported by the Talentia Scholarship Program (Junta de Andalucía, Spain) (MPM), the International Team for Implantology through the ITI Scholarship Program (AL), and the Research Groups \#CTS-138 and \#CTS-583 (Junta de Andalucía, Spain) (All). This work has been also recommended by the PACT (Platelet and Advanced Cell Therapies) Forum Civitatis of the POSEIDO Academic Consortium (Periodontology, Oral Surgery, Esthetic and Implant Dentistry Organization).

\section{References}

[1] G. Pagni, D. Kaigler, G. Rasperini, G. Avila-Ortiz, R. Bartel, and W. V. Giannobile, "Bone repair cells for craniofacial regeneration," Advanced Drug Delivery Reviews, vol. 64, no. 12, pp. 1310-1319, 2012.

[2] P. Galindo-Moreno, M. Padial-Molina, E. Sánchez-Fernández, P. Hernández-Cortés, H.-L. Wang, and F. O’Valle, "Dental implant migration in grafted maxillary sinus," Implant Dentistry, vol. 20, no. 6, pp. 400-405, 2011.

[3] P. Galindo-Moreno, M. Padial-Molina, G. Avila, H. F. Rios, P. Hernández-Cortés, and H.-L. Wang, "Complications associated 
with implant migration into the maxillary sinus cavity," Clinical Oral Implants Research, vol. 23, no. 10, pp. 1152-1160, 2012.

[4] N. G. Janssen, W. L. J. Weijs, R. Koole, A. J. W. P. Rosenberg, and G. J. Meijer, "Tissue engineering strategies for alveolar cleft reconstruction: a systematic review of the literature," Clinical Oral Investigations, vol. 18, no. 1, pp. 219-226, 2014.

[5] M. Padial-Molina, P. Galindo-Moreno, and G. Avila-Ortiz, "Biomimetic ceramics in implant dentistry," Minerva Biotecnologica, vol. 21, no. 3, pp. 173-186, 2009.

[6] M. Padial-Molina, J. T. Marchesan, A. D. Taut, Q. Jin, W. V. Giannobile, and H. F. Rios, "Methods to validate toothsupporting regenerative therapies," Methods in Molecular Biology, vol. 887, pp. 135-148, 2012.

[7] R. Dimitriou, E. Jones, D. McGonagle, and P. V. Giannoudis, "Bone regeneration: current concepts and future directions," BMC Medicine, vol. 9, article 66, 2011.

[8] M. Padial-Molina and H. F. Rios, "Stem cells, scaffolds and gene therapy for periodontal engineering," Current Oral Health Reports, vol. 1, no. 1, pp. 16-25, 2014.

[9] D. G. Phinney and D. J. Prockop, "Concise review: mesenchymal stem/multipotent stromal cells: the state of transdifferentiation and modes of tissue repair-current views," Stem Cells, vol. 25, no. 11, pp. 2896-2902, 2007.

[10] S. Shi, P. M. Bartold, M. Miura, B. M. Seo, P. G. Robey, and S. Gronthos, "The efficacy of mesenchymal stem cells to regenerate and repair dental structures," Orthodontics and Craniofacial Research, vol. 8, no. 3, pp. 191-199, 2005.

[11] M. Dominici, K. Le Blanc, I. Mueller et al., "Minimal criteria for defining multipotent mesenchymal stromal cells. The International Society for Cellular Therapy position statement," Cytotherapy, vol. 8, no. 4, pp. 315-317, 2006.

[12] D. Kaigler, G. Pagni, C.-H. Park, S. A. Tarle, R. L. Bartel, and W. V. Giannobile, "Angiogenic and osteogenic potential of bone repair cells for craniofacial regeneration," Tissue Engineering A, vol. 16, no. 9, pp. 2809-2820, 2010.

[13] P. C. Baer, "Adipose-derived mesenchymal stromal/stem cells: an update on their phenotype in vivo and in vitro," World Journal of Stem Cells, vol. 6, no. 3, pp. 256-265, 2014.

[14] P. C. Baer and H. Geiger, "Adipose-derived mesenchymal stromal/stem cells: tissue localization, characterization, and heterogeneity," Stem Cells International, vol. 2012, Article ID 812693, 11 pages, 2012.

[15] A. Gonshor, B. S. McAllister, S. S. Wallace, and H. Prasad, "Histologic and histomorphometric evaluation of an allograft stem cell-based matrix sinus augmentation procedure," The International Journal of Oral \& Maxillofacial Implants, vol. 26, no. 1, pp. 123-131, 2011.

[16] D. Rickert, S. Sauerbier, H. Nagursky, D. Menne, A. Vissink, and G. M. Raghoebar, "Maxillary sinus floor elevation with bovine bone mineral combined with either autogenous bone or autogenous stem cells: a prospective randomized clinical trial," Clinical Oral Implants Research, vol. 22, no. 3, pp. 251-258, 2011.

[17] S. Sauerbier, D. Rickert, R. Gutwald et al., "Bone marrow concentrate and bovine bone mineral for sinus floor augmentation: a controlled, randomized, single-blinded clinical and histological trial-per-protocol analysis," Tissue Engineering A, vol. 17, no. 17-18, pp. 2187-2197, 2011.

[18] C. E. S. Da Costa, A. A. Pelegrine, D. J. Fagundes, M. De Jesus Simoes, and M. O. Taha, "Use of corticocancellous allogeneic bone blocks impregnated with bone marrow aspirate: a clinical, tomographic, and histomorphometric study," General Dentistry, vol. 59, no. 5, pp. e200-e205, 2011.
[19] M. Gimbel, R. K. Ashley, M. Sisodia et al., "Repair of alveolar cleft defects: reduced morbidity with bone marrow stem cells in a resorbable matrix," Journal of Craniofacial Surgery, vol. 18, no. 4, pp. 895-901, 2007.

[20] D. Kaigler, G. Pagni, C. H. Park et al., "Stem cell therapy for craniofacial bone regeneration: a randomized, controlled feasibility trial," Cell Transplantation, vol. 22, no. 5, pp. 767-777, 2013.

[21] A. A. Pelegrine, C. E. S. da Costa, M. E. P. Correa, and J. F. C. Marques Jr., "Clinical and histomorphometric evaluation of extraction sockets treated with an autologous bone marrow graft," Clinical Oral Implants Research, vol. 21, no. 5, pp. 535$542,2010$.

[22] S. Sauerbier, A. Stricker, J. Kuschnierz et al., "In vivo comparison of hard tissue regeneration with human mesenchymal stem cells processed with either the ficoll method or the BMAC method," Tissue Engineering Part C: Methods, vol. 16, no. 2, pp. 215-223, 2010.

[23] A. Wojtowicz, S. Chaberek, E. Urbanowska, and K. Ostrowski, "Comparison of efficiency of platelet rich plasma, hematopoieic stem cells and bone marrow in augmentation of mandibular bone defects," The New York State Dental Journal, vol. 73, no. 2, pp. 41-45, 2007.

[24] H. Behnia, A. Khojasteh, M. Soleimani et al., "Secondary repair of alveolar clefts using human mesenchymal stem cells," Oral Surgery, Oral Medicine, Oral Pathology, Oral Radiology, and Endodontology, vol. 108, no. 2, pp. el-e6, 2009.

[25] H. Behnia, A. Khojasteh, M. Soleimani, A. Tehranchi, and A. Atashi, "Repair of alveolar cleft defect with mesenchymal stem cells and platelet derived growth factors: a preliminary report," Journal of Cranio-Maxillofacial Surgery, vol. 40, no. 1, pp. 2-7, 2012.

[26] H. F. Cerruti, I. Kerkis, A. Kerkis et al., "Allogenous bone grafts improved by bone marrow stem cells and platelet growth factors: clinical case reports," Artificial Organs, vol. 31, no. 4, pp. 268-273, 2007.

[27] F. Hernández-Alfaro, V. Ruiz-Magaz, P. Chatakun, and R. Guijarro-Martínez, "Mandibular reconstruction with tissue engineering in multiple recurrent ameloblastoma," The International Journal of Periodontics \& Restorative Dentistry, vol. 32, no. 3, pp. e82-e86, 2012.

[28] H. Hibi, Y. Yamada, M. Ueda, and Y. Endo, "Alveolar cleft osteoplasty using tissue-engineered osteogenic material," International Journal of Oral and Maxillofacial Surgery, vol. 35, no. 6, pp. 551-555, 2006.

[29] J. Lee, H.-M. Sung, J.-D. Jang, Y.-W. Park, S.-K. Min, and E.-C. Kim, "Successful reconstruction of $15-\mathrm{cm}$ segmental defects by bone marrow stem cells and resected autogenous bone graft in central hemangioma," Journal of Oral and Maxillofacial Surgery, vol. 68, no. 1, pp. 188-194, 2010.

[30] G. J. Meijer, J. D. de Bruijn, R. Koole, and C. A. van Blitterswijk, "Cell based bone tissue engineering in jaw defects," Biomaterials, vol. 29, no. 21, pp. 3053-3061, 2008.

[31] G. K. Sándor, V. J. Tuovinen, J. Wolff et al., "Adipose stem cell tissue-engineered construct used to treat large anterior mandibular defect: a case report and review of the clinical application of good manufacturing practice-level adipose stem cells for bone regeneration," Journal of Oral and Maxillofacial Surgery, vol. 71, no. 5, pp. 938-950, 2013. 
[32] G. K. Sándor, J. Numminen, J. Wolff et al., “Adipose stem cells used to reconstruct 13 cases with cranio-maxillofacial hardtissue defects," Stem Cells Translational Medicine, vol. 3, no. 4, pp. 530-540, 2014.

[33] S. Sauerbier, B. Giessenhagen, W. Gutwerk et al., "Bone marrow aspirate concentrate used with bovine bone mineral to reconstruct vertical and horizontal mandibular defects: report of two techniques," The International Journal of Oral \& Maxillofacial Implants, vol. 28, no. 5, pp. e310-e314, 2013.

[34] R. Schmelzeisen, R. Gutwald, T. Oshima, H. Nagursky, M. Vogeler, and S. Sauerbier, "Making bone II: maxillary sinus augmentation with mononuclear cells-case report with a new clinical method," British Journal of Oral and Maxillofacial Surgery, vol. 49, no. 6, pp. 480-482, 2011.

[35] Y. S. Shayesteh, A. Khojasteh, M. Soleimani, M. Alikhasi, A. Khoshzaban, and N. Ahmadbeigi, "Sinus augmentation using human mesenchymal stem cells loaded into a $\beta$-tricalcium phosphate/hydroxyapatite scaffold," Oral Surgery, Oral Medicine, Oral Pathology, Oral Radiology and Endodontology, vol. 106, no. 2, pp. 203-209, 2008.

[36] D. Smiler, M. Soltan, and J. W. Lee, "A histomorphogenic analysis of bone grafts augmented with adult stem cells," Implant Dentistry, vol. 16, no. 1, pp. 42-53, 2007.

[37] M. Soltan, D. Smiler, H. S. Prasad, and M. D. Rohrer, "Bone block allograft impregnated with bone marrow aspirate," Implant Dentistry, vol. 16, no. 4, pp. 329-339, 2007.

[38] M. Soltan, D. Smiler, C. Soltan, H. S. Prasad, and M. D. Rohrer, "Bone grafting by means of a tunnel dissection: predictable results using stem cells and matrix," Implant Dentistry, vol. 19, no. 4, pp. 280-287, 2010.

[39] M. Ueda, Y. Yamada, R. Ozawa, and Y. Okazaki, "Clinical case reports of injectable tissue-engineered bone for alveolar augmentation with simultaneous implant placement," The International Journal of Periodontics and Restorative Dentistry, vol. 25, no. 2, pp. 129-137, 2005.

[40] M. Ueda, Y. Yamada, H. Kagami, and H. Hibi, "Injectable bone applied for ridge augmentation and dental implant placement: human progress study," Implant Dentistry, vol. 17, no. 1, pp. 8290, 2008.

[41] C. Wongchuensoontorn, N. Liebehenschel, U. Schwarz et al., "Application of a new chair-side method for the harvest of mesenchymal stem cells in a patient with nonunion of a fracture of the atrophic mandible-a case report," Journal of CranioMaxillofacial Surgery, vol. 37, no. 3, pp. 155-161, 2009.

[42] Y. Yamada, K. Hara, S. Nakamura, M. Ueda, K. Ito, and T. Nagasaka, "Minimally invasive approach with tissue engineering for severe alveolar bone atrophy case," International Journal of Oral and Maxillofacial Surgery, vol. 42, no. 2, pp. 260-263, 2013.

[43] R. F. Heary, R. P. Schlenk, T. A. Sacchieri et al., "Persistent iliac crest donor site pain: independent outcome assessment," Neurosurgery, vol. 50, no. 3, pp. 510-517, 2002.

[44] P. Tessier, "Autogenous bone grafts taken from the calvarium for facial and cranial applications," Clinics in Plastic Surgery, vol. 9, no. 4, pp. 531-538, 1982.

[45] H.-P. Gerber, T. H. Vu, A. M. Ryan, J. Kowalski, Z. Werb, and N. Ferrara, "VEGF couples hypertrophic cartilage remodeling, ossification and angiogenesis during endochondral bone formation," Nature Medicine, vol. 5, no. 6, pp. 623-628, 1999.

[46] A. C. Jones, C. H. Arns, A. P. Sheppard, D. W. Hutmacher, B. K. Milthorpe, and M. A. Knackstedt, "Assessment of bone ingrowth into porous biomaterials using MICRO-CT,' Biomaterials, vol. 28, no. 15, pp. 2491-2504, 2007.

[47] M. Padial-Molina, P. Galindo-Moreno, J. E. Fernández-Barbero et al., "Role of wettability and nanoroughness on interactions between osteoblast and modified silicon surfaces," Acta Biomaterialia, vol. 7, no. 2, pp. 771-778, 2011.

[48] W. Chen, L. G. Villa-Diaz, Y. Sun et al., "Nanotopography influences adhesion, spreading, and self-renewal of human embryonic stem cells," ACS Nano, vol. 6, no. 5, pp. 4094-4103, 2012.

[49] H. F. Rios, Z. Lin, B. Oh, C. H. Park, and W. V. Giannobile, "Cell- and gene-based therapeutic strategies for periodontal regenerative medicine," Journal of Periodontology, vol. 82, no. 9, pp. 1223-1237, 2011.

[50] D. E. Discher, D. J. Mooney, and P. W. Zandstra, "Growth factors, matrices, and forces combine and control stem cells," Science, vol. 324, no. 5935, pp. 1673-1677, 2009.

[51] ASTM, Standard Terminology for Additive Manufacturing Technologies, ASTM, West Conshohocken, Pa, USA, 2012.

[52] S. Bose, S. Vahabzadeh, and A. Bandyopadhyay, "Bone tissue engineering using 3D printing," Materials Today, vol. 16, no. 12, pp. 496-504, 2013.

[53] L. A. Smith and P. X. Ma, "Computer-designed nano-fibrous scaffolds," Methods in Molecular Biology, vol. 868, pp. 125-134, 2012.

[54] C. H. Park, H. F. Rios, Q. Jin et al., "Tissue engineering boneligament complexes using fiber-guiding scaffolds," Biomaterials, vol. 33, no. 1, pp. 137-145, 2012.

[55] C. H. Park, H. F. Rios, Q. Jin et al., "Biomimetic hybrid scaffolds for engineering human tooth-ligament interfaces," Biomaterials, vol. 31, no. 23, pp. 5945-5952, 2010.

[56] M. J. Gupte and P. X. Ma, "Nanofibrous scaffolds for dental and craniofacial applications," Journal of Dental Research, vol. 91, no. 3, pp. 227-234, 2012.

[57] C. Sun, X. Jin, J. M. Holzwarth et al., "Development of channeled nanofibrous scaffolds for oriented tissue engineering," Macromolecular Bioscience, vol. 12, no. 6, pp. 761-769, 2012.

[58] M. Suto, E. Nemoto, S. Kanaya, R. Suzuki, M. Tsuchiya, and H. Shimauchi, "Nanohydroxyapatite increases BMP-2 expression via a p38 MAP kinase dependent pathway in periodontal ligament cells," Archives of Oral Biology, vol. 58, no. 8, pp. 10211028, 2013.

[59] S. T. Becker, H. Bolte, K. Schünemann et al., "Endocultivation: the influence of delayed vs. simultaneous application of BMP-2 onto individually formed hydroxyapatite matrices for heterotopic bone induction," International Journal of Oral and Maxillofacial Surgery, vol. 41, no. 9, pp. 1153-1160, 2012.

[60] L. Ciocca, D. Donati, S. Ragazzini et al., "Mesenchymal stem cells and platelet gel improve bone deposition within CADCAM custom-made ceramic HA scaffolds for condyle substitution," BioMed Research International, vol. 2013, Article ID 549762, 10 pages, 2013.

[61] S. Tarafder, V. K. Balla, N. M. Davies, A. Bandyopadhyay, and S. Bose, "Microwave-sintered 3D printed tricalcium phosphate scaffolds for bone tissue engineering," Journal of Tissue Engineering and Regenerative Medicine, vol. 7, no. 8, pp. 631-641, 2013.

[62] R. Detsch, S. Schaefer, U. Deisinger, G. Ziegler, H. Seitz, and B. Leukers, "In vitro: osteoclastic activity studies on surfaces of 3D printed calcium phosphate scaffolds," Journal of Biomaterials Applications, vol. 26, no. 3, pp. 359-380, 2011. 
[63] X. Liu, J. M. Holzwarth, and P. X. Ma, "Functionalized synthetic biodegradable polymer scaffolds for tissue engineering," Macromolecular Bioscience, vol. 12, no. 7, pp. 911-919, 2012.

[64] J.-H. Jang, T. L. Houchin, and L. D. Shea, "Gene delivery from polymer scaffolds for tissue engineering," Expert Review of Medical Devices, vol. 1, no. 1, pp. 127-138, 2004.

[65] C. A. Ramseier, Z. R. Abramson, Q. Jin, and W. V. Giannobile, "Gene therapeutics for periodontal regenerative medicine," Dental Clinics of North America, vol. 50, no. 2, pp. 245-263, 2006.

[66] S. Ghali, M. P. Dempsey, D. M. Jones, R. H. Grogan, P. E. Butler, and G. C. Gurtner, "Plastic surgical delivery systems for targeted gene therapy," Annals of Plastic Surgery, vol. 60, no. 3, pp. 323332, 2008.

[67] C. H. Park, H. F. Rios, A. D. Taut et al., "Image-based, fiber guiding scaffolds: a platform for regenerating tissue interfaces," Tissue Engineering Part C: Methods, vol. 20, no. 7, pp. 533-542, 2014.

[68] H.-T. Liao, Y.-Y. Chen, Y.-T. Lai, M.-F. Hsieh, and C.-P. Jiang, "The osteogenesis of bone marrow stem cells on mPEG-PCLmPEG/hydroxyapatite composite scaffold via solid freeform fabrication," BioMed Research International, vol. 2014, Article ID 321549, 13 pages, 2014.

[69] S. Catros, J.-C. Fricain, B. Guillotin et al., "Laser-assisted bioprinting for creating on-demand patterns of human osteoprogenitor cells and nano-hydroxyapatite," Biofabrication, vol. 3, no. 2, Article ID 025001, 2011.

[70] J. A. Phillippi, E. Miller, L. Weiss, J. Huard, A. Waggoner, and P. Campbell, "Microenvironments engineered by inkjet bioprinting spatially direct adult stem cells toward muscle- and bone-like subpopulations," Stem Cells, vol. 26, no. 1, pp. 127-134, 2008.

[71] C. Rentsch, B. Rentsch, S. Heinemann et al., "ECM inspired coating of embroidered 3D scaffolds enhances calvaria bone regeneration," BioMed Research International, vol. 2014, Article ID 217078, 15 pages, 2014.

[72] U. Gbureck, E. Vorndran, F. A. Müller, and J. E. Barralet, "Low temperature direct 3D printed bioceramics and biocomposites as drug release matrices," Journal of Controlled Release, vol. 122, no. 2, pp. 173-180, 2007.

[73] S. Sood, S. Gupta, and A. Mahendra, "Gene therapy with growth factors for periodontal tissue engineering-a review," Medicina Oral, Patologia Oral y Cirugia Bucal, vol. 17, no. 2, pp. e301-e310, 2012.

[74] P. Janicki and G. Schmidmaier, "What should be the characteristics of the ideal bone graft substitute? Combining scaffolds with growth factors and/or stem cells," Injury, vol. 42, supplement 2, pp. S77-S81, 2011.

[75] M. Padial-Molina, S. L. Volk, and H. F. Rios, "Periostin increases migration and proliferation of human periodontal ligament fibroblasts challenged by tumor necrosis factor $-\alpha$ and Porphyromonas gingivalis lipopolysaccharides," Journal of Periodontal Research, vol. 49, no. 3, pp. 405-414, 2014.

[76] M. Padial-Molina, S. L. Volk, J. C. Rodriguez, J. T. Marchesan, P. Galindo-Moreno, and H. F. Rios, "Tumor necrosis factor$\alpha$ and Porphyromonas gingivalis lipopolysaccharides decrease periostin in human periodontal ligament fibroblasts," Journal of Periodontology, vol. 84, no. 5, pp. 694-703, 2013.

[77] M. Padial-Molina, S. L. Volk, A. D. Taut, W. V. Giannobile, and H. F. Rios, "Periostin is down-regulated during periodontal inflammation," Journal of Dental Research, vol. 91, no. 11, pp. 1078-1084, 2012.
[78] L. K. Rosselli-Murai, L. O. Almeida, C. Zagni et al., "Periostin responds to mechanical stress and tension by activating the MTOR signaling pathway," PLoS ONE, vol. 8, no. 12, Article ID e83580, 2013

[79] J. Sodek, B. Ganss, and M. D. McKee, “Osteopontin,” Critical Reviews in Oral Biology \& Medicine, vol. 11, no. 3, pp. 279-303, 2000.

[80] K. Matusan-Ilijas, S. Behrem, N. Jonjic, K. Zarkovic, and K. Lucin, "Osteopontin expression correlates with angiogenesis and survival in malignant astrocytoma," Pathology and Oncology Research, vol. 14, no. 3, pp. 293-298, 2008.

[81] C. M. Giachelli, L. Liaw, C. E. Murry, S. M. Schwartz, and M. Almeida, "Osteopontin expression in cardiovascular diseases," Annals of the New York Academy of Sciences, vol. 760, pp. 109126, 1995.

[82] G. F. Weber, S. Ashkar, M. J. Glimcher, and H. Cantor, "Receptor-ligand interaction between CD44 and osteopontin (Eta-1)," Science, vol. 271, no. 5248, pp. 509-512, 1996.

[83] L. F. Raheja, D. C. Genetos, and C. E. Yellowley, "Hypoxic osteocytes recruit human MSCs through an OPN/CD44-mediated pathway," Biochemical and Biophysical Research Communications, vol. 366, no. 4, pp. 1061-1066, 2008.

[84] P. Galindo-Moreno, P. Hernandez-Cortes, J. Aneiros-Fernandez et al., "Morphological evidences of Bio-Oss(R) colonization by CD44-positive cells," Clinical Oral Implants Research, vol. 25, no. 3, pp. 366-371, 2014.

[85] P. Galindo-Moreno, I. Moreno-Riestra, G. Avila et al., "Effect of anorganic bovine bone to autogenous cortical bone ratio upon bone remodeling patterns following maxillary sinus augmentation," Clinical Oral Implants Research, vol. 22, no. 8, pp. 857-864, 2011.

[86] F. O’Valle, M. Peregrina Palomares, V. Crespo Lora et al., "Valoración de la expresión inmunohistoquímica de Musashi-1 en modelo murino de reparación osteoarticular," in Proceedings of the 3rd SCOI International Meeting, pp. 40-41, Spanish College of Oral Implantologists, Granada, Spain, 2014.

[87] M. Heyde, K. A. Partridge, R. O. C. Oreffo, S. M. Howdle, K. M. Shakesheff, and M. C. Garnett, "Gene therapy used for tissue engineering applications," Journal of Pharmacy and Pharmacology, vol. 59, no. 3, pp. 329-350, 2007.

[88] M. L. Fabiilli, C. G. Wilson, F. Padilla, F. M. Martín-Saavedra, J. B. Fowlkes, and R. T. Franceschi, "Acoustic droplet-hydrogel composites for spatial and temporal control of growth factor delivery and scaffold stiffness," Acta Biomaterialia, vol. 9, no. 7, pp. 7399-7409, 2013.

[89] F. M. Martín-Saavedra, C. G. Wilson, R. Voellmy, N. Vilaboa, and R. T. Franceschi, "Spatiotemporal control of vascular endothelial growth factor expression using a heat-shockactivated, rapamycin-dependent gene switch," Human Gene Therapy Methods, vol. 24, no. 3, pp. 160-170, 2013.

[90] C. G. Wilson, F. M. Martín-Saavedra, F. Padilla et al., "Patterning expression of regenerative growth factors using high intensity focused ultrasound," Tissue Engineering Part C: Methods, vol. 20, no. 10, pp. 769-779, 2014.

[91] T. Bielecki and D. M. Dohan Ehrenfest, "Platelet-Rich Plasma (PRP) and Platelet-Rich Fibrin (PRF): surgical adjuvants, preparations for in situ regenerative medicine and tools for tissue engineering," Current Pharmaceutical Biotechnology, vol. 13, no. 7, pp. 1121-1130, 2012.

[92] D. M. D. Ehrenfest, L. Rasmusson, and T. Albrektsson, "Classification of platelet concentrates: from pure platelet-rich plasma 
(P-PRP) to leucocyte- and platelet-rich fibrin (L-PRF)," Trends in Biotechnology, vol. 27, no. 3, pp. 158-167, 2009.

[93] A. Cieslik-Bieleck, J. Choukroun, G. Odin, and D. M. Dohan Ehrenfest, "L-PRP/L-PRF in esthetic plastic surgery, regenerative medicine of the skin and chronic wounds," Current Pharmaceutical Biotechnology, vol. 13, no. 7, pp. 1266-1277, 2012.

[94] M. del Corso, A. Vervelle, A. Simonpieri et al., "Current knowledge and perspectives for the use of Platelet-Rich Plasma (PRP) and Platelet-Rich Fibrin (PRF) in oral and maxillofacial surgery. Part 1. Periodontal and dentoalveolar surgery," Current Pharmaceutical Biotechnology, vol. 13, no. 7, pp. 1207-1230, 2012.

[95] A. Simonpieri, M. Del Corso, A. Vervelle et al., "Current knowledge and perspectives for the use of Platelet-Rich Plasma (PRP) and Platelet-Rich Fibrin (PRF) in oral and maxillofacial surgery part 2: bone graft, implant and reconstructive surgery," Current Pharmaceutical Biotechnology, vol. 13, no. 7, pp. 12311256, 2012.

[96] D. M. Dohan Ehrenfest, T. Bielecki, A. Mishra et al., "In search of a consensus terminology in the field of platelet concentrates for surgical use: platelet-rich plasma (PRP), platelet-rich fibrin (PRF), fibrin gel polymerization and leukocytes," Current Pharmaceutical Biotechnology, vol. 13, no. 7, pp. 1131-1137, 2012.

[97] D. M. Dohan Ehrenfest, G. Sammartino, J. A. Shibli, H. L. Wang, D. R. Zou, and J. P. Bernard, "Guidelines for the publication of articles related to platelet concentrates (Platelet-Rich PlasmaPRP, or Platelet-Rich Fibrin-PRF): the international classification of the POSEIDO," POSEIDO Journal, vol. 1, no. 1, pp. 17-27, 2013.

[98] D. M. Dohan Ehrenfest, T. Bielecki, R. Jimbo et al., "Do the fibrin architecture and leukocyte content influence the growth factor release of platelet concentrates? An evidencebased answer comparing a pure Platelet-Rich Plasma (P-PRP) gel and a leukocyte- and Platelet-Rich Fibrin (L-PRF)," Current Pharmaceutical Biotechnology, vol. 13, no. 7, pp. 1145-1152, 2012.

[99] D. M. Dohan Ehrenfest, M. Del Corso, A. Diss, J. Mouhyi, and J.-B. Charrier, "Three-dimensional architecture and cell composition of a Choukroun's platelet-rich fibrin clot and membrane," Journal of Periodontology, vol. 81, no. 4, pp. 546$555,2010$.

[100] D. M. D. Ehrenfest, A. Diss, G. Odin, P. Doglioli, M.-P. Hippolyte, and J.-B. Charrier, "In vitro effects of Choukroun's PRF (platelet-rich fibrin) on human gingival fibroblasts, dermal prekeratinocytes, preadipocytes, and maxillofacial osteoblasts in primary cultures," Oral Surgery, Oral Medicine, Oral Pathology, Oral Radiology and Endodontology, vol. 108, no. 3, pp. 341352, 2009.

[101] D. M. Dohan Ehrenfest, G. M. de Peppo, P. Doglioli, and G. Sammartino, "Slow release of growth factors and thrombospondin-1 in Choukroun's platelet-rich fibrin (PRF): a gold standard to achieve for all surgical platelet concentrates technologies," Growth Factors, vol. 27, no. 1, pp. 63-69, 2009.

[102] D. M. D. Ehrenfest, "How to optimize the preparation of leukocyte- and platelet-rich fibrin (L-PRF, Choukroun's technique) clots and membranes: introducing the PRF Box," Oral Surgery, Oral Medicine, Oral Pathology, Oral Radiology, Endodontics, vol. 110, no. 3, pp. 275-280, 2010.

[103] D. M. Dohan Ehrenfest, P. Doglioli, G. M. de Peppo, M. Del Corso, and J.-B. Charrier, "Choukroun's platelet-rich fibrin (PRF) stimulates in vitro proliferation and differentiation of human oral bone mesenchymal stem cell in a dose-dependent way," Archives of Oral Biology, vol. 55, no. 3, pp. 185-194, 2010.
[104] M. del Corso and D. M. D. Ehrenfest, "Immediate implantation and peri-implant Natural Bone Regeneration (NBR) in the severely resorbed posterior mandible using Leukocyte- and Platelet-Rich Fibrin (L-PRF): a 4-year follow-up," POSEIDO, vol. 1, no. 2, pp. 109-116, 2013.

[105] R. Toeroek and D. M. D. Ehrenfest, "The concept of screwguided bone regeneration (S-GBR). Part 2: S-GBR in the severely resorbed preimplant posterior mandible using bone xenograft and Leukocyte- and platelet-rich fibrin (L-PRF): a 5year follow-up," POSEIDO, vol. 1, no. 2, pp. 85-92, 2013.

[106] R. Toeroek and D. M. D. Ehrenfest, "The concept of ScrewGuided Bone Regeneration (S-GBR). Part 3: fast screw-guided bone regeneration (FS-GBR) in the severely resorbed preimplant posterior mandible using allograft and Leukocyte- and Platelet-Rich Fibrin (L-PRF): a 4-year follow-up," POSEIDO, vol. 1, no. 2, pp. 93-100, 2013.

[107] Z. Mazor, R. A. Horowitz, M. del Corso, H. S. Prasad, M. D. Rohrer, and D. M. D. Ehrenfest, "Sinus floor augmentation with simultaneous implant placement using Choukroun's plateletrich fibrin as the sole grafting material: a radiologic and histologic study at 6 months," Journal of Periodontology, vol. 80, no. 12, pp. 2056-2064, 2009.

[108] A. Simonpieri, J. Choukroun, M. D. Corso, G. Sammartino, and D. M. D. Ehrenfest, "Simultaneous sinus-lift and implantation using microthreaded implants and leukocyte- and platelet-rich fibrin as sole grafting material: a six-year experience," Implant Dentistry, vol. 20, no. 1, pp. 2-12, 2011.

[109] R. Toeroek, Z. Mazor, M. Del Corso, and D. M. Dohan Ehrenfest, "The concept of Screw-Guided Bone Regeneration (S-GBR). Part 1: from sinus-lift to general applications in the resorbed maxilla and mandible," POSEIDO Journal, vol. 1, no. 2, pp. 69-84, 2013. 

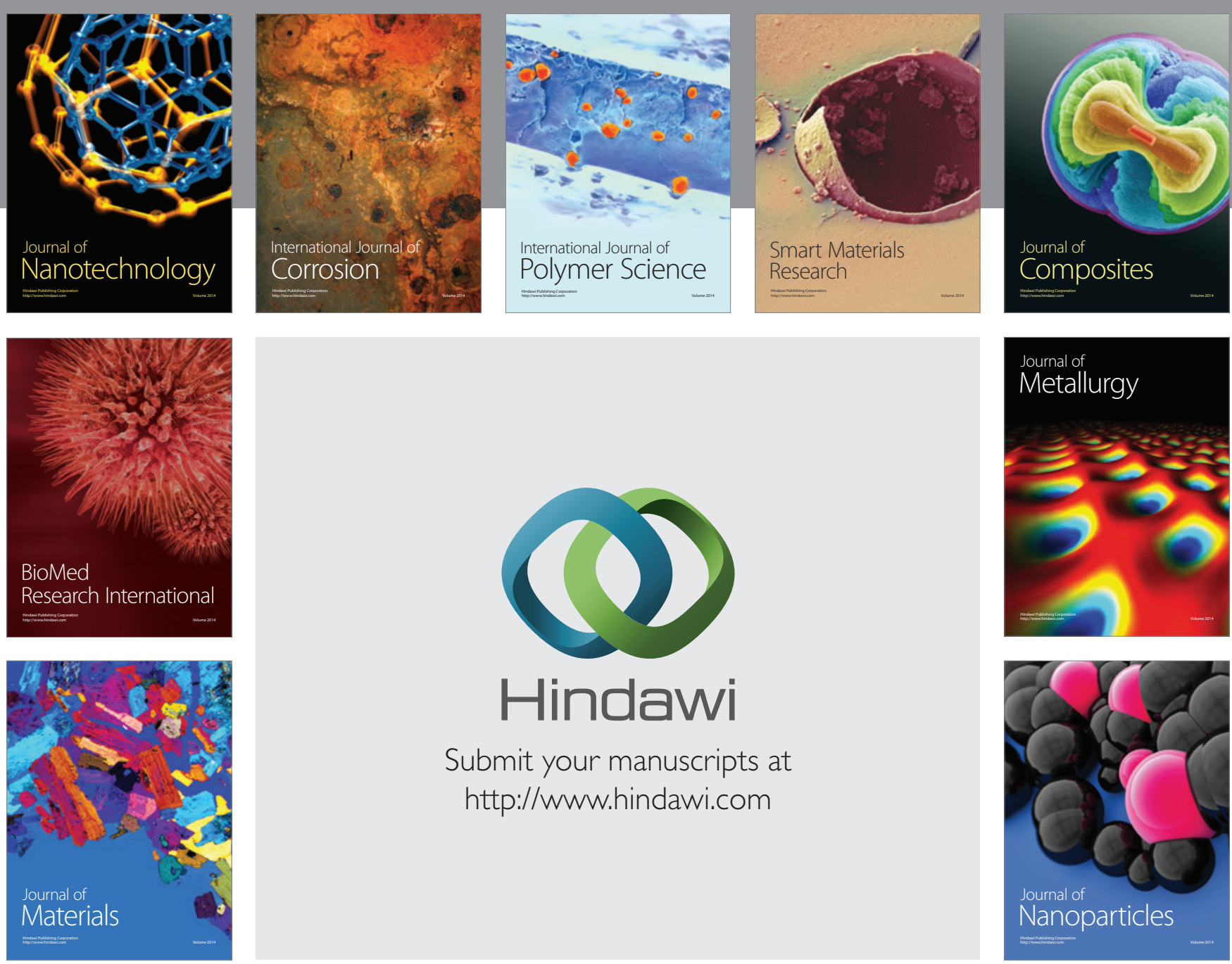

Submit your manuscripts at http://www.hindawi.com
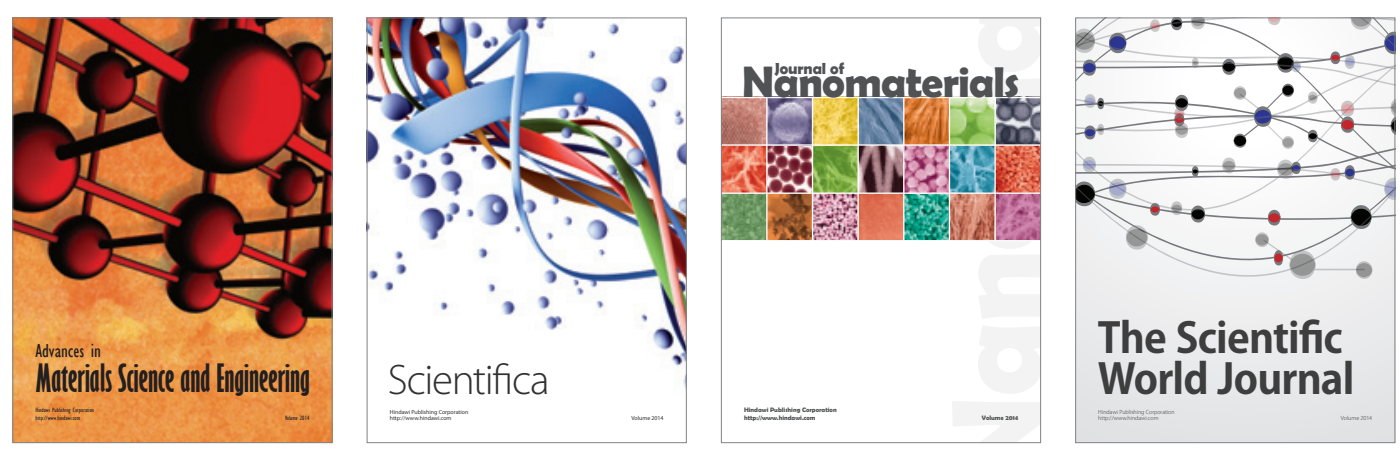

\section{The Scientific World Journal}
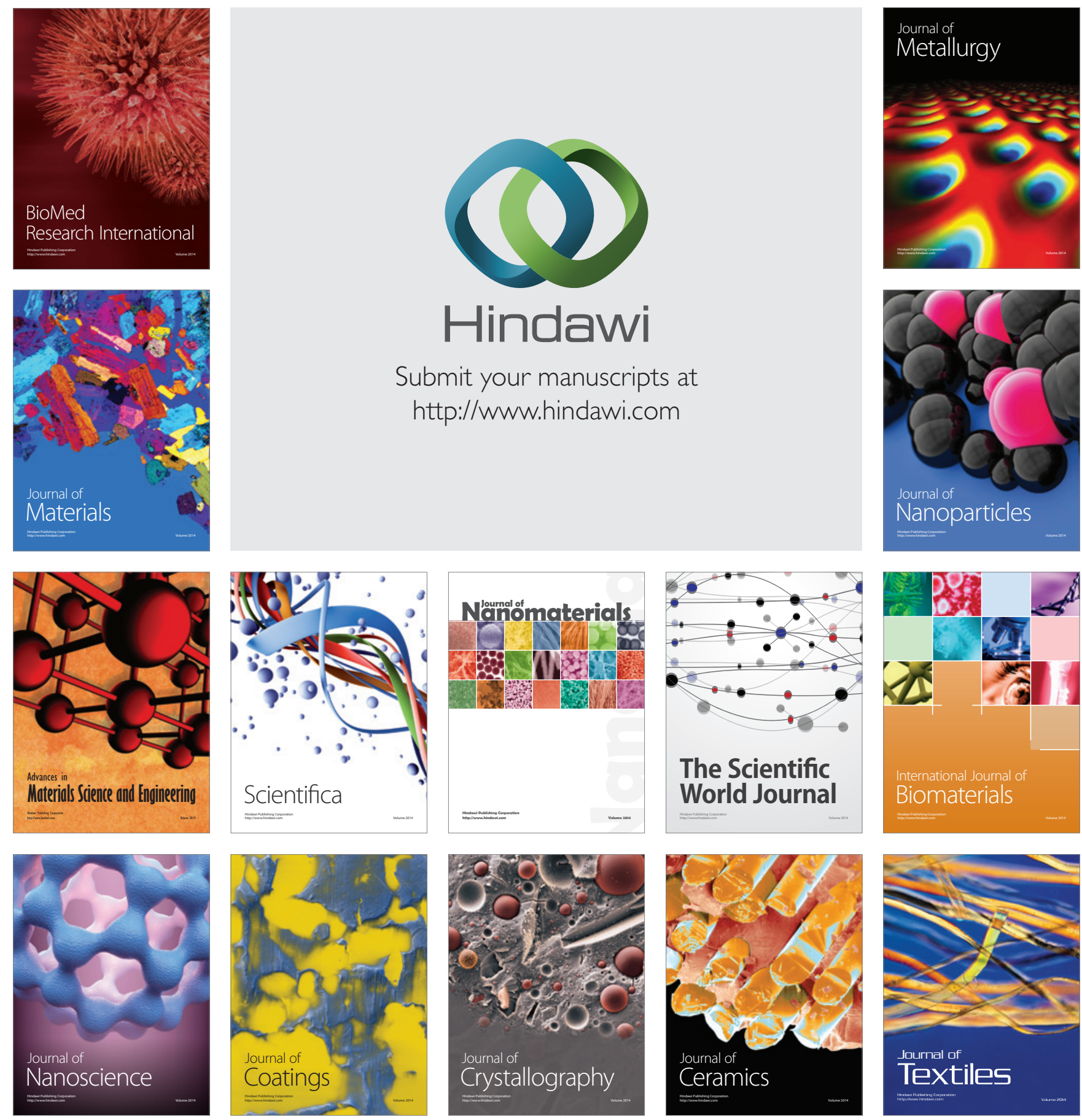